\title{
Research on the Applications of Stage Arrangement and Atmosphere Design for Fashion Show Teaching Activities
}

\author{
Jiarong $\operatorname{Han}^{1}$ \\ ${ }^{1}$ Northeast Dianli University ,Jilin , Jilin 132012 China
}

\begin{abstract}
In this paper, we conduct literature review on the applications of stage arrangement and atmosphere design for fashion show teaching activities. Stage is a collection of music, art, dance and so on many aspects in the integration of art, the stage is to show the beautiful place, so the stage design also need to show "aesthetics" as the goal and direction, and combine into the content of the innovation in the design. Stage artists need to be directed by idea through accurate and perfect, will stage the visual effect be the best. In developing the fashion show time is short, not form a suitable for the teaching system of higher education to cultivate. Professional courses in dance is a professional basic course, teachers are mostly from a professional school graduate, learning dance of professionals for many years. Our proposed methodology will not only solve the issues that teachers lack experience but help the students to enhance their ability easier.
\end{abstract}

Keywords: Fashion Show; Atmosphere Design; Stage Arrangement; Literature Review.

\section{Introduction}

Fashion show is a comprehensive art and also can the independent appreciation of arts. It produces in the prosperity and development of the clothing culture, has experienced hundreds of years of development, formed the enduring form of performance, both commercial and artistic connotation which has broad development prospects. Fashion shows that static clothing obtained the dynamic display of art. As the society in recent years increased demand for fashion show talent, to the employee comprehensive quality requirements are increasing and increases to the requirement of the teaching quality. Fashion show director's planners, designers and organizers of the fashion show. Fashion show director as a fashion show art one of the important factors in a fashion show is responsible for the conception of fashion show theme and choreography clothing series, guiding models rehearsals and the music, sound, stage art, such as voice-over planning and guidance. Practice is the only standard to check the truth and the practice ability is the best teacher. Along with our country joining the world trade organization, China's garment industry is faced with a very good opportunity, due to the lack of high-quality skilled talents in China, most colleges and universities have opened a fashion show professional, applied skilled personnel to develop garments. Although fashion show theoretical knowledge is important, but for garment industry, practice is the criterion for testing performance apparel teaching achievements [1-3].

Fashion show most universities students in learning, the simply and blindly learning fashion show professional theory knowledge, lack of practice, to make our country clothing performance standards far from market demand more and more, the design of fashion show lack of innovative elements and fashion elements, completely unable to meet the requirements of domestic and even international garment industry. Schools in the face of this severe test, must be combined with its own level of fashion show and the demand of market economy, formulate relevant teaching plan, practice teaching to improve students, to cultivate the comprehensive quality of high fashion show talent. There are 
some drawbacks existing in our current teaching activities. (1) Students' professional ability and their own conditions are different. In the training of professional quality of clothing model to learn dancing ability training, dance and fashion are two different nature of the show, but have in common between them is body language as a performance measure to express thoughts and feelings. Exercise fitness unreasonable models can change the original state, improve the flexibility of the body and enhance plasticity and expressiveness of the body. Targeted exercise to improve the professional core ability quality model is necessary. (2) Evaluation of partial factors did not pay attention to the degree of efforts to change. Fashion show professional teaching evaluation to stay in the shape of the shape, the special quality of students skills based, grades, performance check, did not pay attention to the students' learning attitude, team work, efforts and progress of the assessment, how to quantify body shape, performance based evaluation index, such as reasonable for students learning evaluation and related Suggestions are students to further study and improve the way of scientific research. (3) The conflict between practice teaching and theoretical teaching. In the daily teaching high school students in addition to professional extracurricular, and general class, expand class. For the professional training form, performance, dress and performance form and image creation, dance associated with the physical practice of teaching time is very nervous. And these specialized courses need teaching penetration, the combination of theory and practice of the combination of theory and practice to the students' innovation ability and personality is the key [4]. How to make full use of existing practice teaching time is the key to improve the professional development.

To overcome the drawbacks mentioned above, we conduct literature review on the applications of stage arrangement and atmosphere design for fashion show teaching activities in this paper. Stage of the design to have distinct theme, and the design of the entire process must revolve around the theme of the stage, such different performance or the party are endowed with different meaning, therefore, the stage of design also needs to have its own characteristics to innovation breakthrough. Stage art design should be highlighted in it created an atmosphere of the ideas of the script, image and artistic style. Stage performance can have a variety of forms such as art, music, dancing, and different forms in different time and space can show the different content, so in design stage, must be the combination of form and content. In the following sections, we will discuss the issues more in-depth.

\section{Our Research and Literature Review}

The Importance of Atmosphere Design. The stage arrangement is the key of the fashion show, performance success, by the mere force of playwright-director is not enough which also need the tacit understanding between the internal departments to cooperate. In the fashion show arrangement work, must first determine the performance of the scheme, and then further study of the performance art style, ideological content and model of the image. In this way can the overall performance have a deep understanding, thus the performing style and theme will be the comprehensive. Design is the soul of the stage of sexual content, and the stage decoration is visual communication design is the most intuitive performance. Modern society, communication between people and communication is the most main is the use of visual and language form, before there is no language communication, is relying on visual perception to assess a person or a thing, so the adornment of the stage design is very important. Designers need to some specific idea of the content, in accordance with the requirements of the theme highlights the idea of stylist, under the premise of the theme expression and interpretation through the stage of graphic design. In the performance of the design, also has the 
dynamic and static balance. Choreography model display line wants to be coordinated movement, the process of locating the performance appearance, can't deviate from the stage, also can't overlap, congregate at a specific point on the stage space shape point as far as possible to the staggered, by reasonably using the stage of dynamic balance, make the whole stage will flow.

Under normal circumstances, people to familiar things can cause strong visual sense of difference, but also because of some things you can't let others itself is clear found its essence, in the face of these situations, deconstruction appears very important. Will these things mean separation from the separate parts of a detailed analysis, and to combine these ingredients to restructure and, will object to shift from familiar to strange, resulting in a new shock feeling. From order to order into a new order, there will always be new content of the transformation process, this process is the process of creative inspire which is able to provide a steady stream of stage design ideas. The principles of the stage design will be summarized as the follows. (1) Atmosphere and space environment required to create performance, fully reflects the theme of the show. Director, models and other auxiliary department of basic task is to reflect the theme of the fashion show, are going to have a fashion show layout is designed according to the content of the theme of the fashion show and the collocation of sets of equipment, lighting, space form and tableaux. (2) Satisfy the audience's aesthetic requirements and improves the audience's aesthetic taste. With live performances in the choreography highlight space properties on the basis of the environment, adjust the proportion of the space contrast unity with the actual situation to deal with relationship, the change of light in the use of color art to attention, the audience enjoy the performance results in a harmonious environment atmosphere, meet their aesthetic needs, mentally physically to the audience the greatest satisfaction..
The Review of Stage Arrangement. From the stage art design, good stage tend to show and actor additive greatly, from this year's big party and drama, we can see that practice feedback to our conclusion. Stage art design technology in recent years has greatly improved and the late effect of the development of technology and LEO technology, the traditional stage art design center is also quietly changing, especially the scenery gradually weakened, and the effect of light. However, has not changed is the actor in the stage performance modelling and costumes, their core importance is self-evident there for all to see. Stage art design under the restriction of the content, has the poem of sentient beings, interested in painting, poem picturesque artistic effect, fully embody the emotion in the form of sexual performance, although at the time of stage design should pay attention to in the script content, plot development, director for the general guiding principles, and depending on the stage the activities of the characters and plot development to set up the special scenery environment, but these are inseparable from the dance beautiful personality. Among the choreography, personality comes from our real life environment, in order to show life, reduction, use simple, unique color do excel, stage to the audience leave deep impression and true feelings.

Stage design is no longer use the method of discreteness, designed for a play or act of the play a scene. But with the comprehensive method, according to the guiding principle of ideological content to design a comprehensive structure, it has the function of self-adjusting and changing to meet the needs of performed different scenarios, form a coherent, variable space of drama. Space of size, shape, direction, closing degree and the space structure that is the affect the performance of emotional characteristics, such as depression and empty, crowded and loneliness, mystery and cordial which let the choreography space aesthetic transcendence, go beyond the limitations of the stage space. 
In the choreography of space control ability, can provide functional support for performers, more can be the perfect foil the vivid performance. Stage task is according to the content of the script and performance requirements, in the unity of artistic conception by means of a variety of plastic arts, create the environment and the external image of the role play, rendering the stage atmosphere. Therefore, the stage arrangement is more than important for the fashion show activities.

The Novel Teaching Pattern with the Multimedia. Multimedia as a traditional teaching mode is an effective auxiliary means, it is the characteristics and advantages of conventional teaching methods cannot match. Multimedia technology is to make the text, images, audio, and video and other media and by computer integrated technology. It has the advantages of other media cannot replace with scientific, greatly improve the students' learning interest and learning initiative, to promote the change of teaching method and teaching ideas. Scene import purpose is to stimulate students' interest in learning, to establish learning psychological tendency. Previous teaching is the teacher speak, students listen to, so that the teaching content boring, narrow range of knowledge, students are not interested in, the teaching effect is not obvious. And after using the multimedia teaching, we can put some models show knowledge in the form of courseware, which makes the students easy to accept and the expanded aspect of knowledge and improve the students' interest in learning.

It will learn the training of the overall portfolio to demonstrate to the students. Through the multimedia courseware can put teachers in real teaching problems and difficulty in teaching intention comprehensively and systematically in a very intuitive way. Students are difficult to understand the complete body movements, it is not easy to quickly build a complete action representation and the teacher too much repeated demonstration and explanation are easy to make students produce the wrong understanding. The teachers use multimedia courseware to demonstrate the technology of clear, the image using slow motion, with the courseware teaching means such as mirror, stop playback in combination with explanation, demonstration and display, it can help students to see details of each action, faster and more accurately establish the movement appearance, highlighted the grasp of the key and difficult movements which will improve the teaching effect, shorten the teaching process.

The development of modern network technology, making the number of network data and network sharing degree have been greatly improved, some teaching materials needed and can be easily found on the web. Such as dada style, rural style clothing technique of expression, such as how to organize a conference can search on the website that the teachers can make full use of network resources and multimedia equipment to carry out a variety of teaching activities. Milan fashion show analysis, for example, we can organize students to watch video, appreciate the model performance, to analyze its artistic characteristics, and group discussion. The real world test has shown that this approach will not only enhance the performance of the teachers but help students understand faster.

The Stage Arrangement and Atmosphere Design based Teaching Model. Fashion show music to have a clear tendency of style, this style tends to consistent with the performance of clothing style. Because when the music style and clothing style unifies, the audience's visual and auditory to echo and strengthening, the art of fashion show force will naturally become more powerful, visual effect is more prominent. Fashion show is supposed to be the life of the performing arts, fashion show the action of the most life breath, and higher than life. Clothing design show success not only lies in the clothing itself, also lies in the human body dynamic display, and the factors to design a more all-round way. Here, how to grasp fashion 
designers design intent and design scheme of the scene became a clothing model hold the key. In some ways, the model on the catwalk is for clothing design, the design requirement model must pay attention to improve their cultural and artistic accomplishment and draw nutrition from other art forms which will enrich themselves. Model only by constantly improve their self-cultivation and art cultivation, can play freely on the stage, performing properly and make the perfect union with god which will dress more perfectly show people, make the performance more verve. Only in this way, the teaching of fashion show will be effective.

\section{CONCLUSIONS}

In this paper, we conduct literature review on the applications of stage arrangement and atmosphere design for fashion show teaching activities. Along with our country recently joining the world trade organization, China's garment industry is faced with a very good opportunity. Clothing for the performing arts covers a lot of art, they contact each other and influence each other, in the teaching of these factors are short of one cannot, otherwise it will affect the integrity and objectivity. For fashion show professional teaching reform in colleges and universities which will also need the teacher continuously explore in the teaching practice, to adapt to the industry and the requirements of the times. Our proposed methodology will not only solve the issues that teachers lack experience but help the students to enhance their ability easier which will be meaningful.

\section{References}

[1] Zhan Z. Study on educational environment in basketball teaching activities in colleges and universities of Fujian Province[J]. Contemporary Sports Technology, 2014.

[2] Laureti T, Secondi L, Biggeri L. Measuring the efficiency of teaching activities in Italian universities: An information theoretic approach[J]. Economics of Education Review, 2014, 42(C).

[3] Wang D Q, Yan-Xia J I, Education S O, et al. A Research on Effective Classroom Teaching Activities in Rural Primary and Secondary Schools[J]. Journal of Shijiazhuang University, 2014.

[4] OECD. How Much Time Do Teachers Spend on Teaching and Non-teaching Activities? [J]. Education Indicators in Focus,

2015 . 